\title{
The Income Elasticity of Gambling in Australia and New Zealand
}

\author{
Jamie Davies
}

\begin{abstract}
This paper analyses disposable income as it relates to consumer demand for gambling products in Australia and New Zealand from Financial years (FY) 1998 to 2008. The hypothesis is that income elasticity of demand for gambling products is greater than one i.e. gambling products are a luxury good. The alternate hypothesis is that the income elasticity of demand for gambling products are less than one and are classed as either necessity or inferior goods. Data compiled by the Queensland Treasury and Trade department, the Australian Bureau of Statistics, Statistics New Zealand and the New Zealand Department of Internal Affairs was used to calculate income elasticities for all gambling products. The results indicate that income elasticity for gambling products varies over time and is greater than one pre FY2003 and less than one post FY2003. However, once the change in market share of different gambling products and the large increase in supply in the gaming industry sector (pre FY2003) was accounted for, income elasticities were estimated to be less than one in support of the alternate hypothesis.
\end{abstract}




\section{Introduction and hypothesis}

The gambling industry is a big business in both Australia and New Zealand and has grown considerably over the last three decades (Worthington et al., 2007). As of 2014, the gambling industry contributed $1.05 \%$ of Australia's Gross Domestic Product (GDP) (Australasian Gaming Council, 2015) and was categorized under the Arts and Recreation Sector in New Zealand which as a whole - contributed 1.6\% towards New Zealand's GDP (Australasian Gaming Council, 2015). Revenues generated by Australia totalled \$AU 43 billion (Australasian Gaming Council, 2015) and in New Zealand \$NZ 2 billion, in 2014 (Dia.govt.nz, 2015).

Gambling is considered a leisure activity for many in both of these developed countries, and as a result, one of the many factors that affect demand for gambling products is levels of disposable income. Around 70\% of Australians participated in gambling in 2009 (Productivity Commission, 2010).

Income elasticity of demand for a product measure the responsiveness of demand to changes in disposable income (Investopedia, 2004).

The purpose of this research paper is to consider two hypothesis. Using gambling industry statistics in both Australia and New Zealand as well as disposable income, population distribution and inflation data for the two countries, the hypothesis being tested is that gambling is classified as a luxury good i.e. the income elasticity of demand of gambling products is greater than one. The alternate hypothesis is that gambling products are either a necessity or inferior goods in that they have income elasticity's between one and zero (necessity) or below zero (inferior).

By determining the income elasticity of gambling products or by determining periods of time where this income elasticity has changed, the gambling industry can analyse their marketing/business strategies over time in order to improve profits. This in turn, will increase the GDP of each nation. 
Governments (especially state) are interested in forecasting future tax revenues derived from the gambling industry in order to accurately budget as well as internalise some of the negative externalities associated with the gambling industry (problem gambling, social costs).

As such, estimates of disposable income, and the effect of changes in disposable income on consumer spending need to be incorporated into any multi-factor model used to predict future tax revenues.

Furthermore, if income elasticities of gambling goods are found to be greater than one then this may shape government policy in other areas, such as welfare, in order to mitigate some of the social costs associated with the industry.

\section{Theory and literature review}

Gambling is often considered a controversial topic due to the presence of negative externalities in the form of poor socio-economic and addictive outcomes for some individuals, historical involvement by organised crime syndicates and the attitudes of many people in society.

However, in many countries, with changing attitudes towards gambling as a recreation, governments have been called upon and have successfully created legal gambling industries and have internalised some of the negative externalities placed on society as a result of gambling. One of the primary benefits of creating legal gambling industries is the government revenue received from taxation of gambling industry profits.

Many studies have been conducted on the factors affecting gambling demand, the causes of problem gambling and the effect of changes in disposable income on consumption of different gambling products.

The Swiss Institute of Comparative Law (2006) noted that in the European Union, demand for gambling services has been increasing rapidly due to increasing amounts of discretionary income since World War 2 and an increase in acceptance of gambling (resulting in governments regulating/establishing gambling industries). 
Layton and Worthington (1999), noted the relatively greater emphasis that Australian governments (particularly state) have placed on gambling related revenues than most comparable countries. They have tried to incorporate many socio-economic factors to determine gambling expenditure, of which household income was one.

Kaizeler and Faustino, (2011) estimated income elasticities for lottery products in data from eighty countries including Australia and New Zealand. They concluded that higher income class countries (such as Australia and New Zealand) spend less on gambling products than poorer countries and that there is an inverted "U" shape between per capita sales and GDP per capita indicating that the income elasticity of lottery products changes over time (support for both the hypothesis and the alternate hypothesis) as countries get richer. Due to the grouping of countries and presentation of broad statistics it is unclear the exact income elasticity of these two countries as calculated by Kaizeler and Faustino.

Garret and Coughlin (2008) studied income elasticities of demand of lottery tickets of three states in the US over time. Their findings indicate that income elasticities of lottery products do change over time and range from close to unit elastic to negative elasticity depending on state, time and lottery product (support for alternate hypothesis). Whereas Garret and Kolesnikova (2014) determined that income elasticities for lottery goods were above one in some states of the US once differences in local costs of living were accounted for (in support of the hypothesis).

Worthington et al., 2007, examined all gambling types in Australia by analysing the ABS Household expenditure survey and concluded that income source is more important than the level of income in determining household gambling expenditure. Other factors identified include age, wealth, gender and ethnicity and that expenditure varied wildly across different types of gambling activity.

This study is considerably different from other studies due to its concentration on Australia and New Zealand gambling industries, utilisation of broad population statistics to determine income elasticities and most importantly - it analysis of all types of legal gambling within these two economies. 


\section{Data and Approach}

The data examined was restricted within a period of 10 years from financial years $1997 / 98$ to 2007/2008. In both Australia and New Zealand financial years run from 1st July to the 30th of June in the following year. This particular sub set of data was chosen due to the relative stability in the economy with strong economic growth (see Figure 1) with a variety of disposable income changes (See Figure 2). The expenditure behaviour observed during the global financial crisis (circa 2008) is also excluded from this data set due to difficulties in isolating and controlling for all economic variables.

Income elasticity estimates were calculated using the formula:

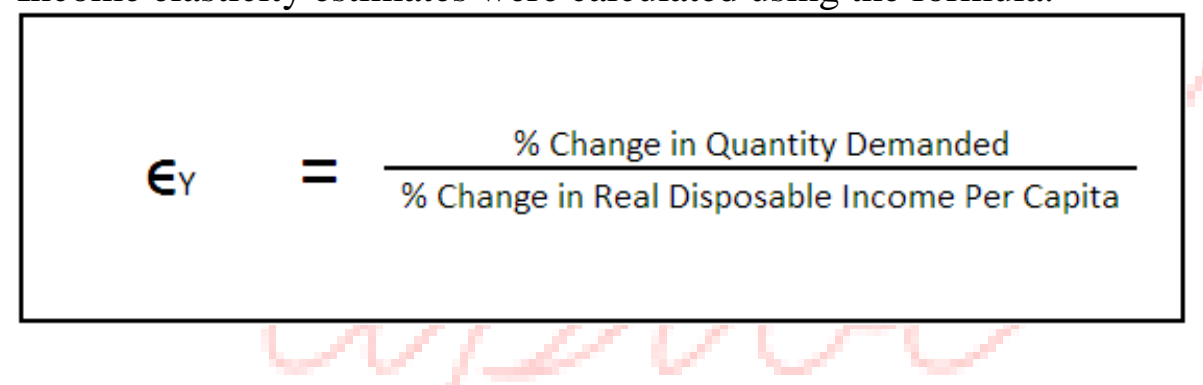

Percentage change in quantity demanded was estimated from real gambling expenditures per person of legal gambling age. Expenditures were sourced from Australian Gambling Statistics 29th Edition (Queensland Treasury and Trade, 2014) for Australia and Gambling Expenditure Statistics published by the Department of Internal Affairs in New Zealand (Dia.govt.nz, 2015).

Gambling expenditures are the net losses from gambling that customers accrue. Actual turnover i.e. the reinvestment of winnings and the subsequent losses were not used, as expenditure was considered a more realistic proxy for demand of gambling products due to differences in mental accounting. Mental accounting refers to the fact that individuals treat money differently based on its source (Investopedia, 2005) and as such consumers are more likely to spend winnings in high turnover gambling products, than they would they're regular income. If total turnover was used as a proxy the data would be skewed against gambling products with higher turnover due to the reduction in risk aversion when spending winnings. 


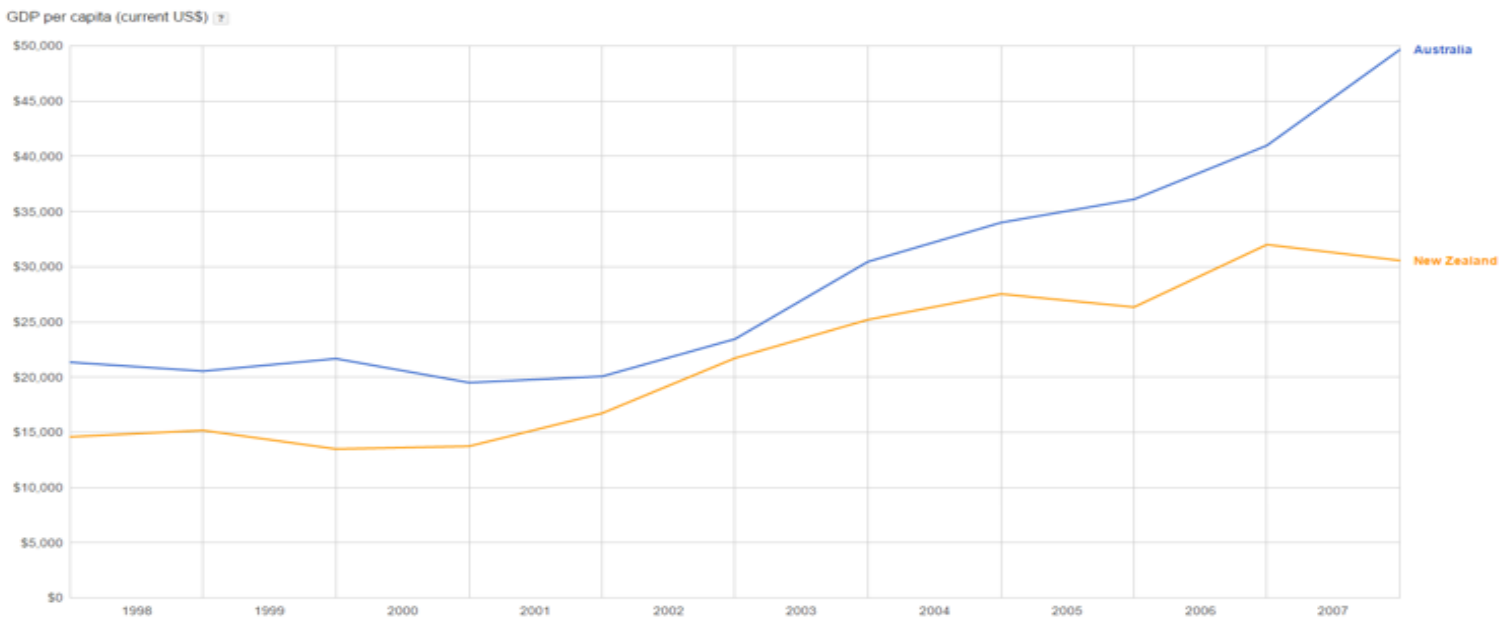

Figure 1: GDP growth per capita of Australia and New Zealand between 1998 and 2007. Source: Google.com 2015

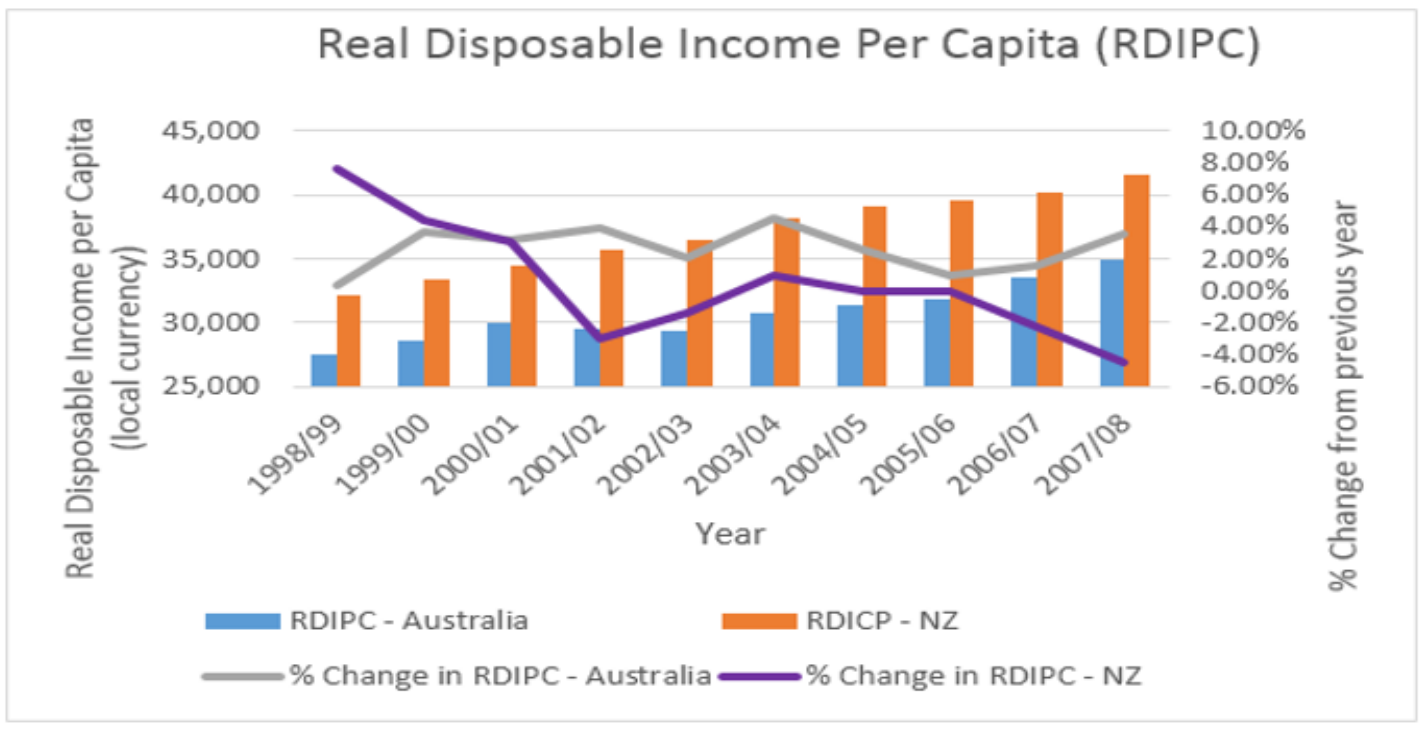

Figure 2: Real disposable income per capita (RDICP) values (in local currency) and the year on year changes in RDICP. 
For Australia, gambling age demographics (persons over 18 years of age) and total disposable income figures were sourced from Australian Gambling Statistics 29th Edition. Total population estimates were obtained from the Australian Bureau of Statistics (2015). Consumer Price Index Data was also sourced from the Australian Bureau of Statistics and was used to adjust all disposable incomes and expenditures to 2007/2008 prices.

For New Zealand, gambling age (18+), total population and disposable income estimates were obtained from Statistics New Zealand (2015) and CPI deflators to adjust all expenditures to 2007/2008 values, were obtained from the Reserve bank of New Zealand (2015).

The raw data used for the calculations are presented in Appendix I and II.

\section{Results and Analysis}

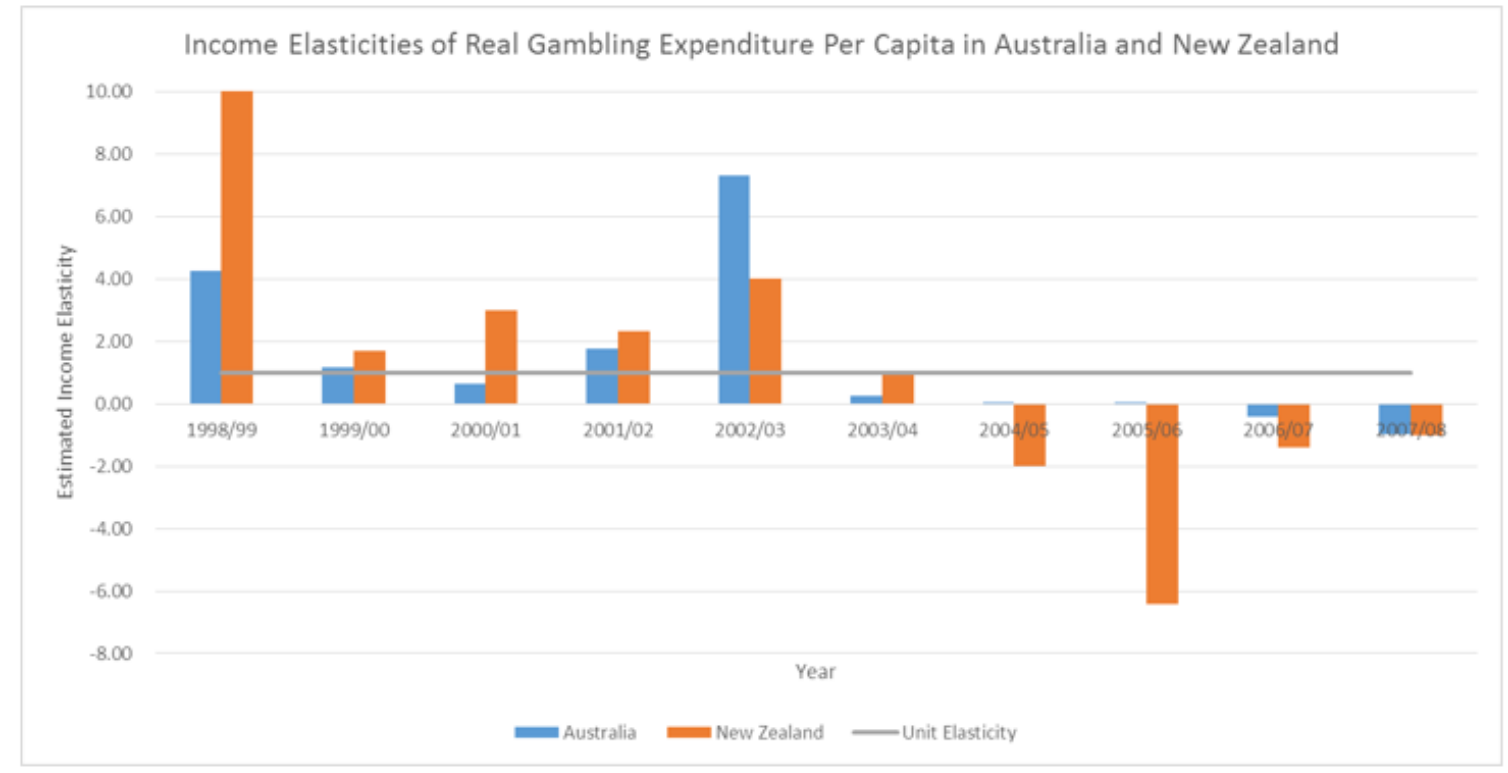

Figure 3: Estimated Income Elasticities of Demand for all gambling products in Australia and New Zealand. 
The Income Elasticises for all gambling products was calculated and are presented in Figure 3.

From the Figure 3 it is observed that for both countries similar trends are apparent with higher income elasticities estimated pre 2002/2003 (in support of the hypothesis) and lower elasticities (in support of the alternate hypothesis) after 2002/2003.

As per the literature review, there is a high degree of product differentiation between different gambling products. Many factors affect the demand for a particular gambling product. In order to further define this shift from high income elasticity in the first half the period to lower elasticities in the second half, gambling expenditure was separated into four major product categories:

- $\quad$ Lotteries - including scratchies, state run lotteries and tatts lotto

- $\quad$ Sports Betting - including horses, greyhounds and major sporting events online or ontrack.

- Casinos - all expenditure occurring at a licensed venue

- $\quad$ Gaming - all other gambling activities either in person or online such as electronic gaming machines (EGMs), keno, bingo etc.

Figure 4 presents the changing composition of gambling demand in Australian and New Zealand economies as well as the real expenditures per capita for different gambling products. The breakdown of gambling product expenditure was taken from Australian Gambling Statistics 29th Edition and Gambling Expenditure Statistics - dia.govt.nz.

As can be seen from Figure 4, the biggest change to both countries' spending habits is the rise of gaming expenditure as a proportion to total expenditure. In Australia, all other gambling expenditure proportions remain fairly stable and in New Zealand expenditure on lottery and sports betting decreases. It appears that this change in market share of gaming machines is driving the trends observed in total gambling expenditure income elasticities. By combining all non-gaming expenditure and calculating income elasticities the following trends are observed. 


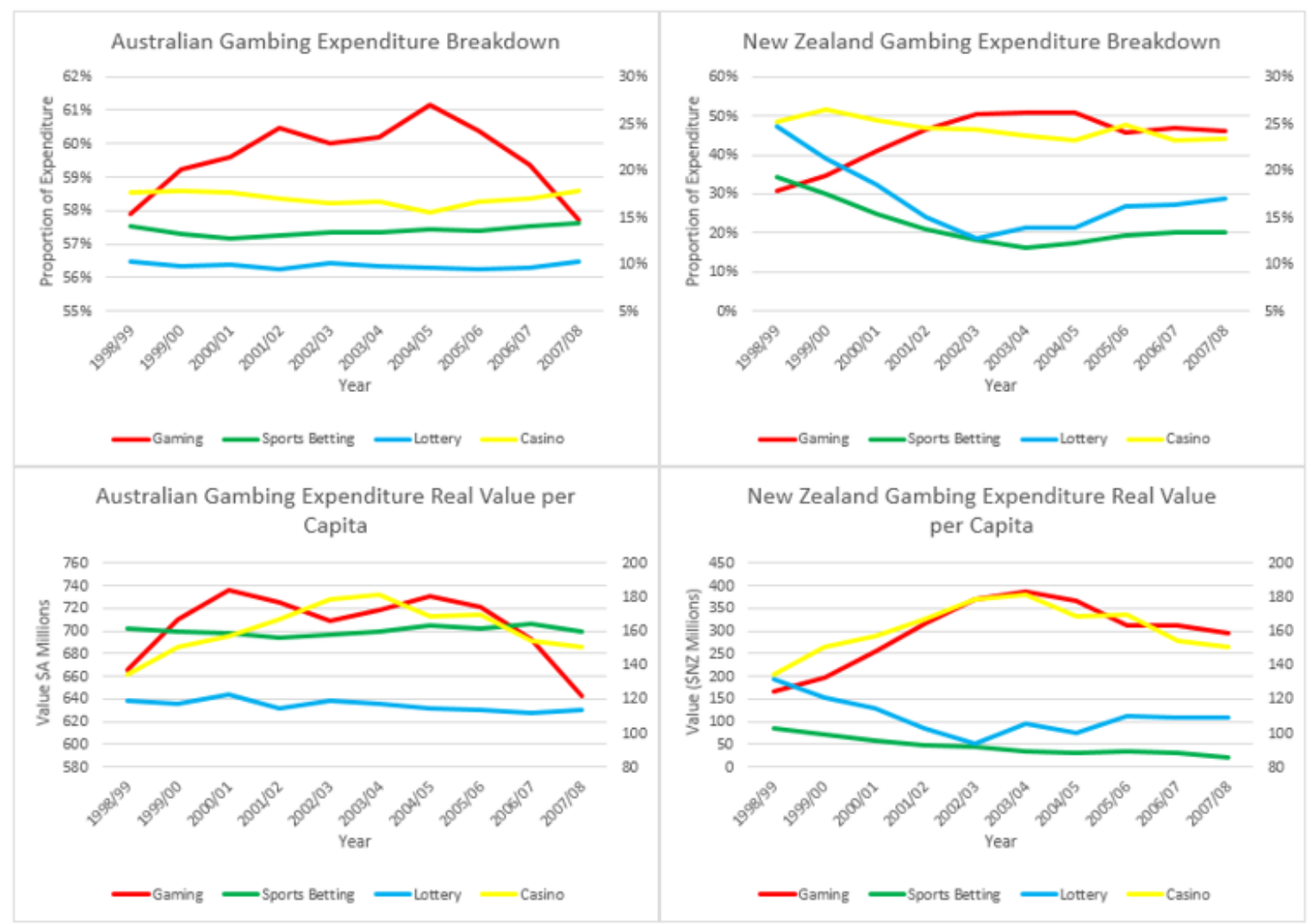

Figure 4: Proportion of different gambling product expenditure in both economies over time as well as the actual value of this expenditure on each gambling product.

From Figure 5, for the majority of years, income elasticities of demand for non-gaming products are below one supporting the alternate hypothesis.

The income elasticities for gaming products exhibit the same trend observed for total gambling expenditure (Figure 6) with a calculated correlation to total gambling elasticity of 0.9813 (Aus) $0.9963(\mathrm{NZ})$. 
DPIBE, Dec 2015

Gambling Elasticity in AU and NZ

Income Elasticities of Real Non-Gaming Gambling Expenditure Per Capita in Australia and New Zealand

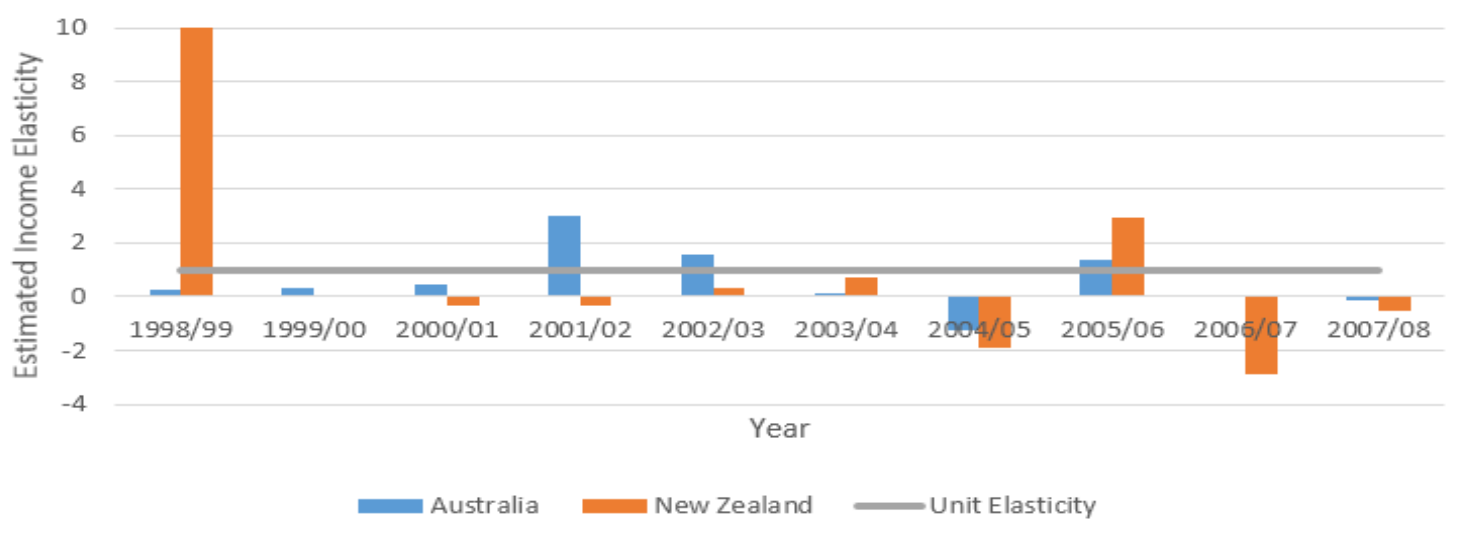

Figure 5: Estimated Income Elasticity for Non-Gaming gambling products in Australia and New Zealand.

Income Elasticities of Real Gaming Expenditure Per Capita in Australia and New Zealand
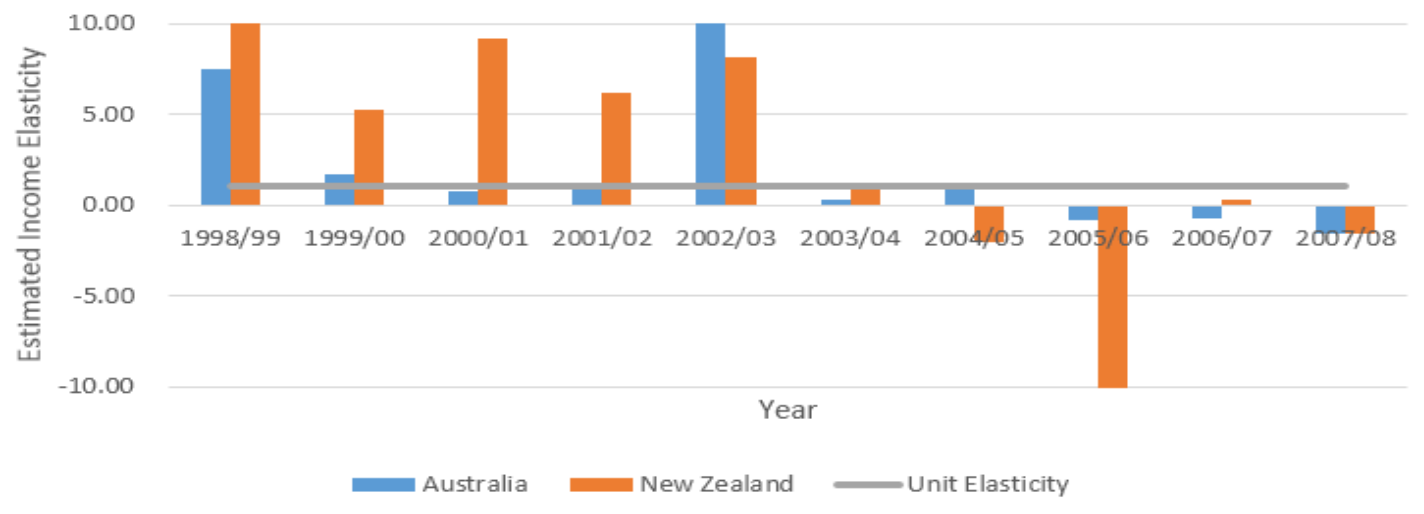

Figure 6: Estimated Income Elasticity for gaming Products in Australia and New Zealand.

10 
For income elasticity calculations, for all gambling product categories, see Appendix III.

Gaming expenditures are driven by exposure to consumers and availability of gaming machines. After it was recognised that EGM's are associated with higher levels of problem gambling and other social costs as documented in a lot of studies (Social Research Centre, 2013, Lund, 2009 and Dickerson and Hinchy, 1988) EGM numbers were reduced through caps and a reduction in licensing. The Australian Productivity Commission Report on Gambling (1999) stated:

"there is sufficient evidence from many different sources to suggest a significant connection between greater accessibility - particularly to gaming machines - and the greater prevalence of problem gambling”. (Productivity Commission 1999. p8.31)

The reported figures on operating EGMs outside of casinos in Australia and New Zealand indicate that EGM numbers reached their peak in 2003. After this time, EGM numbers have declined significantly in both countries (See Figure 7 and Figure 8).

As a result, capital investment and industry expansion needs to be considered when examining income elasticities of demand for gambling products. When gaming machine numbers are not increasing rapidly (such as post 2003) income elasticity for gaming products is less than one supporting the alternate hypothesis and following a similar trend to other gambling products.

When gaming machine numbers are increasing rapidly, the availability of gaming machines and the opportunities to gamble increase. As documented, EGM gambling is one of the most addictive forms of gambling with some of the highest social costs. This increased occurrence of problem gambling may be contributing to increasing the income elasticity of gaming demand. The rapid number of gaming machines may also have been occurring in new markets where local and state legislation has been loosened, presenting a novelty factor associated with a new product along with the increased accessibility to gaming machines as opposed to other forms of gambling. This novelty factor could also explain why demand seems particularly responsive to changes in income. Once EGM numbers have stabilised and no new markets are being created (such as in the period in Australia between FY2002 and FY2005) demand and 
income elasticity remain below one and the product is classed as a necessity/inferior good in support of the alternate hypothesis.

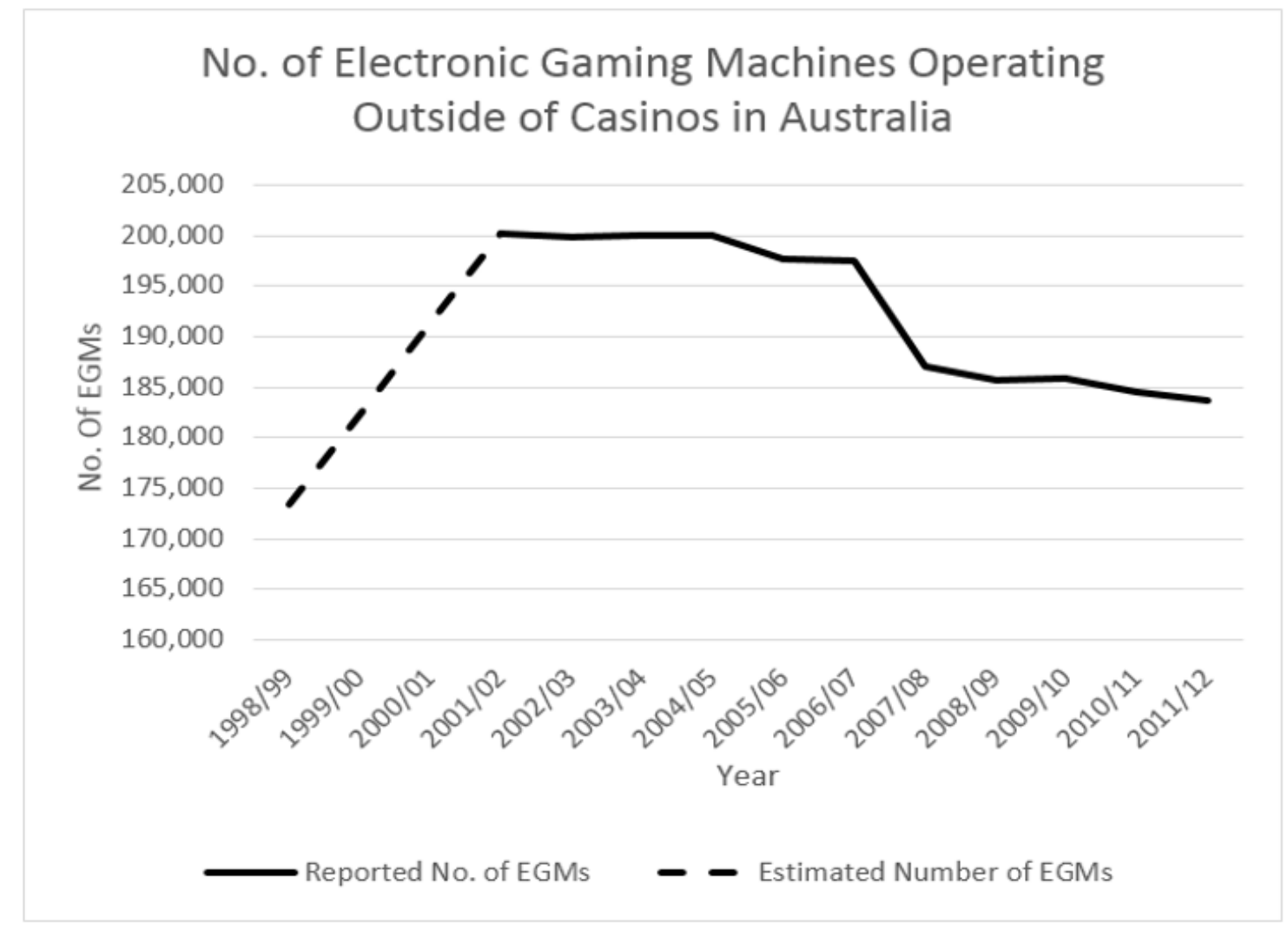

Figure 7: Number of operating EGM machines outside of casinos in Australia. Reported numbers between 2001/2002 to 2011 and 2012 were taken from Australian Gambling Statistics 1986-87 to 2011-2012 29th edition. The total number of EGMS operating in 1998/99 was reported as 184,526 (Productivity Commission, 2010, p2.25) with casino EGM numbers assumed to be the same as reported in 2001/2002. Linear interpolation was used to estimate non-casino gaming machine numbers for 1999-2002. 
Gaming Machines Numbers: June 1994 to March 2015 at 3-Monthly Intervals

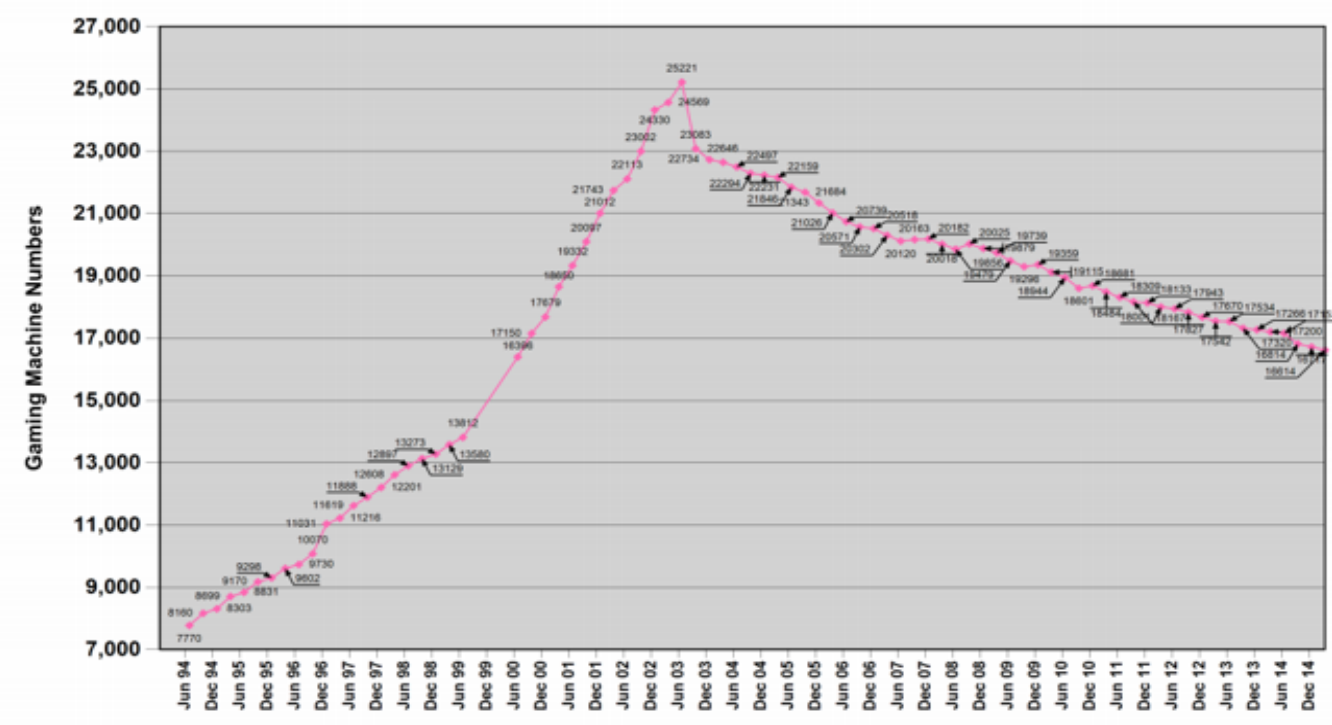

Report generated on : 2 Aprill 2015

Figure 8: Operating EGM numbers in New Zealand (Source: Dia.govt.nz, 2015).

\section{Conclusion and limitations}

In times of constant supply and similar opportunities to purchase gambling products, the evidence supports the alternate hypothesis and gambling products are not luxury items. For the study period, the majority of estimated income elasticities are less than one.

Limitations on the estimations occur due to using gambling expenditure as a proxy for demand. In both cases, gambling expenditure estimates were derived from tax revenues from the gambling industry for each country. As such it was assumed that expenditures were attributed to local populations. However, some portion of that expenditure will be attributed to tourist 
dollars (with a different associated change in disposable income) spent at these local destinations - accounting for some of the noise seen in the estimates. Gambling expenditure is also a product of supply and demand (not just demand) so in order to use as a proxy for demand, changes in supply need to be accounted for.

Illegal and backyard gambling was also not considered in these calculations. Illegal gambling in Australia and New Zealand also includes online gambling that is operated by overseas firms. This could potentially be a significant expenditure of Australians and New Zealanders but is very difficult to track and has not been accounted for.

Broad population data was used to estimate changes in disposable income. The actual consumers of gambling products may have different disposable income attributes to that of the average population. There is some evidence to suggest that low socio economic groups have higher income elasticities of demand for gambling products (Kaizeler and Faustino, 2011). Micro-economic data was not accounted for in this study.

The small sample size of ten observations means that statistical tests on the results were unreliable. A larger sample population needs to be further investigated either from different time periods (with changes in other factors accounted for) or from other developed countries with similar characteristics.

Finally, the period selected represents a time when both economies were expanding and gambling industries are well established. Income elasticities may change significantly based on consumer sentiment when countries have been in a prolonged recession (establishment of consumer "belt tightening") or when new gambling industries are newly established (novelty of new entertainment). 


\section{References}

Abs.gov.au, (2015). 3105.0.65.001 - Australian Historical Population Statistics, 2014. [online] Available at:

http://www.abs.gov.au/AUSSTATS/abs@.nsf/DetailsPage/3105.0.65.0012014?

OpenDocument [Accessed 5 May 2015].

Abs.gov.au, (2015). 6401.0 - Consumer Price Index, Australia, Mar 2015. [online] Available at:http://www.abs.gov.au/AUSSTATS/abs@.nsf/Latestproducts/6401.0Main\%20Featur es6Mar\%202015 opendocument\&tabname $=$ Summary \& prodno $=6401.0 \&$ issue $=$ Mar $\% 2$ $02015 \&$ num $=\&$ view $=$ [Accessed 5 May 2015].

Australasian Gaming Council, (2015). AGC Database Chapter 7 - The Contribution of Australia's Gambling Industries (2013/14). [online] Available at: https://www.austgamingcouncil.org.au/agc-database [Accessed 5 May 2015].

Australasian Gaming Council, (2015). AGC Database Chapter 8 - The Contribution of New Zealand's Gambling Industries (2013/14). [online] Available at: https://www.austgamingcouncil.org.au/agc-database [Accessed 5 May 2015].

Dia.govt.nz, (2015). Gambling Expenditure Statistics - dia.govt.nz. [online] Available at: http://www.dia.govt.nz/diawebsite.nsf/wpg_URL/Resource-material-Information-WeProvide-Gambling-Expenditure-Statistics [Accessed 5 May 2015].

Dia.govt.nz, (2015). Timeline of Gaming Machine Numbers from June 1994 - dia.govt.nz. [online] Available at: http://www.dia.govt.nz/diawebsite.nsf/wpg_URL/Resourcematerial-Information-We-Provide-Timeline-of-Gaming-Machine-Numbers-from-June1994 [Accessed 5 May 2015].

Dickerson, M. and Hinchy, J. (1988). The prevalence of excessive and pathological gambling in Australia. Journal of Gambling Behavior, 4(3), pp.135-151.

Garrett, T. and Coughlin, C. (2008). Inter-Temporal Differences in the Income Elasticity of Demand for Lottery Tickets. SSRN Journal.

Garrett, T. and Kolesnikova, N. (2014). Local Price Variation and the Income Elasticity of Demand for Lottery Tickets. Public Finance Review.

Google.com, (2015). World Development Indicators-Google Public Data Explorer. [online] Available 
at:https://www.google.com/publicdata/explore?ds=d5bncppjof8f9_\&met_y=ny_gdp_pc ap_cd\&idim=country:NZL:AUS:CAN\&hl=en\&dl=en\#!ctype=l\&strail=false \&bcs=d\&n selm=h\&met_y=ny_gdp_pcap_cd\&scale_y=lin\&ind_y=false\&rdim=region\&idim $=$ cou ntry:NZL:AUS\&ifdim=region\&tstart=894556800000\&tend $=1210176000000 \& \mathrm{hl}=\mathrm{en}$ US\&dl=en\&ind=false [Accessed 5 May 2015].

Investopedia, (2004). Income Elasticity of Demand Definition | Investopedia. [online] Available at: http://www.investopedia.com/terms/i/incomeelasticityofdemand.asp [Accessed 5 May 2015].

Investopedia, (2005). Mental Accounting Definition | Investopedia. [online] Available at: http://www.investopedia.com/terms/m/mentalaccounting.asp [Accessed 5 May 2015].

Kaizeler, M. and Faustino, H. (2011). Is the Lottery Product an Inferior Good in Higher Income Countries? International Journal of Economics and Finance, 3(4).

Layton, A. and Worthington, A. (1999). The Impact of Socio-economic Factors on Gambling Expenditure. Int J of Social Economics, 26(1/2/3), pp.430-440.

Lund, I. (2009). Gambling Behavior and the Prevalence of Gambling Problems in Adult EGM Gamblers when EGMs are Banned. A Natural Experiment. Journal Gambling Studies, 25(2), pp.215-225.

Productivity Commission. (1999) Australia's Gambling Industries. Report No 10. Canberra: Commonwealth of Australia

Productivity Commission, (2010). Gambling Productivity Commission Inquiry Report Volume 1. Canberra: Commonwealth of Australia

Queensland Treasury and Trade, (2014). Australian Gambling Statistics 1986-87 to 2011-2012, 29th edition, Government Statistician, Queensland Treasury and Trade

Rbnz.govt.nz, (2015). Inflation Calculator. [online] Available at: http://www.rbnz.govt.nz/monetary_policy/inflation_calculator/[Accessed 5 May 2015].

The Social Research Centre, (2013). Gambling Prevalence in South Australia (2012).

Stats.govt.nz, (2015). Disposable income. [online] Available at: http://www.stats.govt.nz/browse_for_stats/snapshots-of-nz/nz-progressindicators/Home/Economic/disposable-income.aspx [Accessed 5 May 2015]. 
Stats.govt.nz, (2015). Browse - Infoshare - Statistics New Zealand. [online] Available at: http://www.stats.govt.nz/infoshare/SelectVariables.aspx?pxID=0dcb218c-ae7c-43db8185-2376948f17b9 [Accessed 5 May 2015].

Swiss Institute of Comparative Law, (2006). STUDY OF GAMBLING SERVICES IN THE INTERNAL MARKET OF THE EUROPEAN UNION. European Commission, 2006.

Worthington, A., Brown, K., Crawford, M. and Pickernell, D. (2007). Gambling participation in Australia: findings from the national Household Expenditure Survey. Review of Economics of the Household, 5(2), pp.209-221. 